\title{
Influence of Weather Conditions on the Onset of Spontaneous Pneumothorax in the Region of Sousse (Tunisia): Analysis of Time Series
}

\author{
Sana Aissa (iD, 1,2 Maher Maoua, ${ }^{2,3}$ Salsabil Selmi, ${ }^{1,2}$ Wafa Benzarti, ${ }^{1,2}$ Imen Gargouri, ${ }^{1,2}$ \\ Ahmed Abdelghani, 1,2 Abdelhamid Garrouche, 1,2 Abdelaziz Hayouni, ${ }^{1,2}$ \\ Mohamed Kahloul (DD, ${ }^{2,4}$ Walid Naija, ${ }^{2,4}$ Nejib Mrizek, ${ }^{2,3}$ and Mohamed Benzarti ${ }^{1,2}$ \\ ${ }^{1}$ Pneumology Department, University Farhat Hached Hospital, Sousse, Tunisia \\ ${ }^{2}$ University of Sousse, Faculty of Medicine Ibn Jazzar, Sousse, Tunisia \\ ${ }^{3}$ Occupational Medicine Department, University Farhat Hached Hospital, Sousse, Tunisia \\ ${ }^{4}$ Anesthesia Intensive Care Unit, University Sahloul Hospital, Sousse, Tunisia
}

Correspondence should be addressed to Sana Aissa; dr.aissa.sana@gmail.com

Received 23 February 2019; Accepted 9 April 2019; Published 7 May 2019

Academic Editor: Pankaj K. Bhavsar

Copyright (C) 2019 Sana Aissa et al. This is an open access article distributed under the Creative Commons Attribution License, which permits unrestricted use, distribution, and reproduction in any medium, provided the original work is properly cited.

Introduction. Weather conditions were implicated in the onset of spontaneous pneumothorax (SP). Aim. Investigate the influence of weather conditions on the onset of SP. Methods. A total of 200 patients with SP in Sousse (Tunisia) were enrolled in the study between January 2010 and December 2014. An analysis of two time series (meteorological data and pneumothorax cases) was performed. Data on weather conditions were collected daily throughout the 5-year period. Results. A comparison of the mean temperature between days with and without SP showed significantly higher temperatures during the days with SP. A decrease of $1 \%$ in the relative humidity one day lag (D-1) was associated with an increase in the risk of SP by $1.6 \%(\mathrm{p}=0,02)$. The occurrence of clusters was associated significantly with higher temperature averages on the same days. This same observation was made regarding the mean duration of sunshine two days before the cluster onset $(\mathrm{p}=0.05)$. The occurrence of storms two days before clusters was also significantly associated with a risk multiplied by 1.96. Conclusion. There was a correlation between clusters of spontaneous pneumothorax and weather conditions in the region of Sousse-Tunisia.

\section{Introduction}

1.1. Background and Rationale. Spontaneous pneumothorax (SP) is frequent and its incidence is increasing. It is a respiratory disease that may be severe $[1,2]$. Pneumothorax is defined as the entry of air into the pleural space. Spontaneous pneumothorax may be primary, occurring in patients without clinically apparent lung disease, or secondary, arising as a complication of antecedent lung disease [3-6]. Exact pathogenesis is partially known. Most authors state that a spontaneous pneumothorax results from the rupture of a bubble of blebs or an emphysema bubble that is localized in the visceral pleura [7]. The rupture of this bubble occurs when a transpulmonary pressure gradient is present $[8,9]$.
However, little is known about the factors that trigger the rupture of the blebs and bullae that occur in SP. Previous studies have suggested that seasonal variations and meteorological factors may possibly influence the incidence of SP. While some studies have linked atmospheric pressure and decreasing humidity with an increased incidence of SP, others have reported no association between the occurrence of SP and climatic conditions, such as changes in atmospheric pressure, temperature, and humidity.

Some authors have shown that the occurrence of a spontaneous pneumothorax can be influenced by certain climatic variations [9]. Other studies have highlighted the impact of other factors, such as scuba diving, exposition to loud music, or a roller coaster ride [10]. 
Climatic changes in atmospheric pressure, temperature, or humidity may influence the incidence of pneumothorax [11].

1.2. Objective. The aim of the present study is to explore relationships between the occurrence of spontaneous pneumothorax and the variation of meteorological parameters (mean temperature, atmospheric pressure, relative humidity, duration of sunshine, rainfall, and storms) among adults in Sousse (Tunisia) during a 5-year period. This study was designed to investigate the relationship between the occurrence of clusters and the variability of meteorological parameters.

\section{Methods}

2.1. Study Design. We conducted a study of 2 time series (meteorological parameters and cases of pneumothorax) over a period from January $1^{\text {st }}, 2010$ to December 31, 2014. There was no need for an ethics committee approval, since the lack of patients' contact or intervention.

2.2. Setting. Patients hospitalized with a diagnosis of spontaneous pneumothorax between 1 January 2010 and 31 December 2014 were enrolled this study. Patients were treated for spontaneous pneumothorax in the pneumology department, in Farhat Hached Hospital in Sousse, and Anesthesia Intensive Care Unit in Sahloul Hospital in the region of Sousse during the five years of the study representing the two public structures supporting patients for this pathology.

2.3. Participants. Only patients with spontaneous pneumothorax, whether idiopathic, secondary, or relapsing, residing in the governorate of Sousse during the week preceding pneumothorax were included.

Patients with induced pneumothorax (posttraumatic or iatrogenic) and those transferred from another geographic area not under the same meteorological conditions were excluded.

2.4. Variables. For the purposes of the study, two separate synoptic sheets were used: (1) a first sheet relating to the daily meteorological data which included the following variables: date, season, mean temperature, mean temperature one day lag (D-1), average temperature two days lag (D-2), average relative humidity, average relative humidity one $\mathrm{D}-1$, average relative humidity at $\mathrm{D}-2$, mean atmospheric pressure, mean atmospheric pressure at D-1, mean atmospheric pressure at D-2, average duration of sunshine, average duration of sunshine at D-1, average duration of sunshine at D-2, the occurrence of thunderstorms, occurrence of precipitation, occurrence of pneumothorax, and daily number of pneumothorax and (2) a second sheet relating to the medical data including identification of the patients, sex, age, smoking status, localization of the pneumothorax, medical history, date of occurrence of pneumothorax, evolution, and recurrence.
2.5. Data Sources and Measurements. Meteorological data were obtained from the National Institute of Meteorology (NIM) from the meteorological station Monastir-Airport for the agglomeration of Sousse located at $14 \mathrm{Km}$ and this distance allows the extrapolation of measured data to the region of Sousse with good validity [12]. They concern, namely, the average daily temperature in degrees $\left({ }^{\circ} \mathrm{C}\right)$, the average relative humidity (\%), the average duration of sunshine (hours), the average atmospheric pressure expressed in hectopascal $(\mathrm{hPa})$, the occurrence of thunderstorms, and the occurrence of precipitation (rainfall).

In addition to patients, a time series of all days of the study period was compiled with daily averages of all measurable meteorological variables of interest as well as daily weather events.

2.5.1. Bias. A selection bias is noted. In fact, patients included have been identified in the university hospitals where the management of SP is carried out in the region of Sousse. Patients with SP in private clinics were not included.

2.5.2. Study Size. During the study period, the study included convenience retrospectively consecutive patients treated for spontaneous pneumothorax.

2.6. Quantitative Variables. In our study, the dependent variable was the occurrence of pneumothorax, approached in two different ways: the occurrence of one or more episodes of pneumothorax, at a given date, which was considered as a positive response (presence of pneumothorax) and a count data, corresponding to the number of pneumothorax per day during the study period $(0,1,2 \ldots)$.

On the other hand, a "cluster" was defined by a period less than or equal to 3 days between two episodes of spontaneous pneumothorax. Every day between the first episode and the last episode of pneumothorax was enrolled in this cluster.

The independent variables were the meteorological data. These data were recorded for all days included in the study. Associations between pneumothorax events and meteorological data of the same day (D0), one day lag (D-1), and two days lag (D-2) were studied.

2.7. Statistical Methods. In the descriptive study, frequencies and percentages were calculated for the qualitative variables as well as means, standard deviation, medians, quartiles, and range of extreme values for quantitative variables.

For the comparison of means, Student's " $t$ " test was used for paired or independent series averages. Anova's one-factor test was applied for the comparison of several averages.

The frequency comparison was performed by the Pearson's Chi-square test. The study of the relationship between two quantitative variables was performed by the Pearson's correlation coefficient.

For time series analysis, the Poisson generalized linear model (GLM) (Log-linear) was used with, as a dependent variable, a count data represented by the number of pneumothorax per day, after verification of the Poisson distribution. A multiple binary logistic regression was performed, 
TABLE 1: Demographic and clinical characteristics of patients with spontaneous pneumothorax in Sousse, Tunisia, 2010-2014 ( $\mathrm{n}=200$ ).

\begin{tabular}{|c|c|c|}
\hline Variable & & $\mathrm{n}(\%)$ \\
\hline \multirow{2}{*}{ Gender } & (i) Male & 191(95.5) \\
\hline & (ii) Female & $9(4.5)$ \\
\hline \multirow{3}{*}{ Respiratory medical history } & Asthma & $2(1)$ \\
\hline & COPD & $12(6)$ \\
\hline & Interstitial lung disease & $1(0,5)$ \\
\hline Non respiratory medical history & & $50(25)$ \\
\hline No medical history & & $137(67.5)$ \\
\hline Smoking & & $162(81)$ \\
\hline \multirow{3}{*}{ Localization of the pneumothorax } & Right & $100(50$ \\
\hline & Left & $99(49.5)$ \\
\hline & Bilateral & $1(0.5)$ \\
\hline \multirow{2}{*}{ Nature of pneumothorax } & Spontaneous idiopathic pneumothorax & $151(75.5)$ \\
\hline & Spontaneous secondary pneumothorax & $49(24.5)$ \\
\hline \multirow{2}{*}{ Abundance of pneumothorax } & Partial pneumothorax & $53(26.5)$ \\
\hline & Total pneumothorax & $147(73.5)$ \\
\hline
\end{tabular}

TABle 2: Mean values for meteorological variables in Sousse, Tunisia, 2010-2014.

\begin{tabular}{lcccc}
\hline Variable & Mean & SD & Minimum & Maximum \\
\hline $\begin{array}{l}\text { Ambient temperature } \\
\left({ }^{\circ} \mathrm{C}\right)\end{array}$ & $20.6^{\circ} \mathrm{C}$ & $6.01^{\circ} \mathrm{C}$ & 6 & 36 \\
\hline Relative humidity (\%) & 65.55 & 9.9 & 28 & 92 \\
\hline $\begin{array}{l}\text { Atmospheric pressure } \\
(\mathrm{hPa})\end{array}$ & 1015.43 & 5.31 & 996.98 & 1032.22 \\
\hline Rainfall (mm) & 321 & & & \\
\hline Sunshine $(\mathrm{h})$ & 11.97 & 1.69 & 9.44 & 14.35 \\
\hline
\end{tabular}

with, as a dependent variable, the absence or presence of pneumothorax at a given date.

For all statistical tests, the significance level of p-value was set at 0.05. All statistical analyses were performed using SPSS 20.0 software (IBM Corp. Released 2011. IBM SPSS Statistics for Windows, Version 20.0. Armonk, NY: IBM Corp).

\section{Results}

3.1. Participants. Throughout the study period, 200 spontaneous pneumothoraxes were collected.

3.2. Descriptive Data. The study population was relatively young with a mean age of $28 \pm 17.11$ years and the most represented age group was between 21 and 40 years.

Of the 200 patients admitted for SP, 191 (95.5\%) were male patients. Smoking was noticed among 162 (81\%) patients. In regard to comorbidities, $1 \%$ of patients had a diagnosis of asthma, $6 \%$ had chronic obstructive pulmonary disease (COPD), and $0.5 \%$ had interstitial lung disease. SP was idiopathic among 151 (75.5\%) patients and secondary among $49(24.5 \%)$. SP was total in $73.5 \%$ of cases and partial in $26.5 \%$ of cases.
Table 1 shows a summary profile of the study population.

Table 2 shows the means for five climatic variables during the five-year study period: temperature $\left(20.6^{\circ} \mathrm{C}\right)$, relative humidity $(65.55 \%)$, atmospheric pressure $(1015.43 \mathrm{hPa})$, rainfall $(321 \mathrm{~mm})$, and duration of sunshine (11,97 hours).

\subsection{Outcome Data}

3.3.1. Seasonality of Spontaneous Pneumothorax. The occurrence of SP was significantly associated with the season. Indeed, the highest number of pneumothorax was noted during the summer with 61 cases $(32.4 \%)$ compared to 50 cases in spring (26.6\%), 47 cases in autumn, and only 30 cases $(16 \%)$ in winter $(\mathrm{p}=0.015)$ (Figure 1$)$.

Comparing the onset of pneumothorax during summer to the other seasons, a higher risk was noted with an OR $=1.44$ (95\% CI [1.04-1.99]) and $\mathrm{p}=0.0027$. This association was greater while comparing warm seasons (spring-summerautumn) and cold season (winter), with a risk of occurrence of SP during the relatively warm seasons 1.81 times greater than in winter $(\mathrm{p}=0.004, \mathrm{OR}=1.81(95 \% \mathrm{CI}[1.2-2.72]))$.

\subsection{Meteorological Parameters Effects on the Onset of Spontaneous Pneumothorax}

3.4.1. Mean Temperature. The comparison of mean temperatures between days with and without pneumothorax showed significantly higher temperatures during the days of occurrence of this disease with $p=0.021$. The same observation was noted by comparing the mean temperatures one day and two days before the onset of pneumothorax with $\mathrm{p}=0.006$ and $\mathrm{p}=0.011$, respectively.

Figure 2 shows the distribution of the different average temperatures according to the number of cases observed.

Poisson GLM regression showed a significant increased risk of occurrence of a pneumothorax of $3.4 \%$ for each temperature rise of $1^{\circ} \mathrm{C}$. This association was observed for 


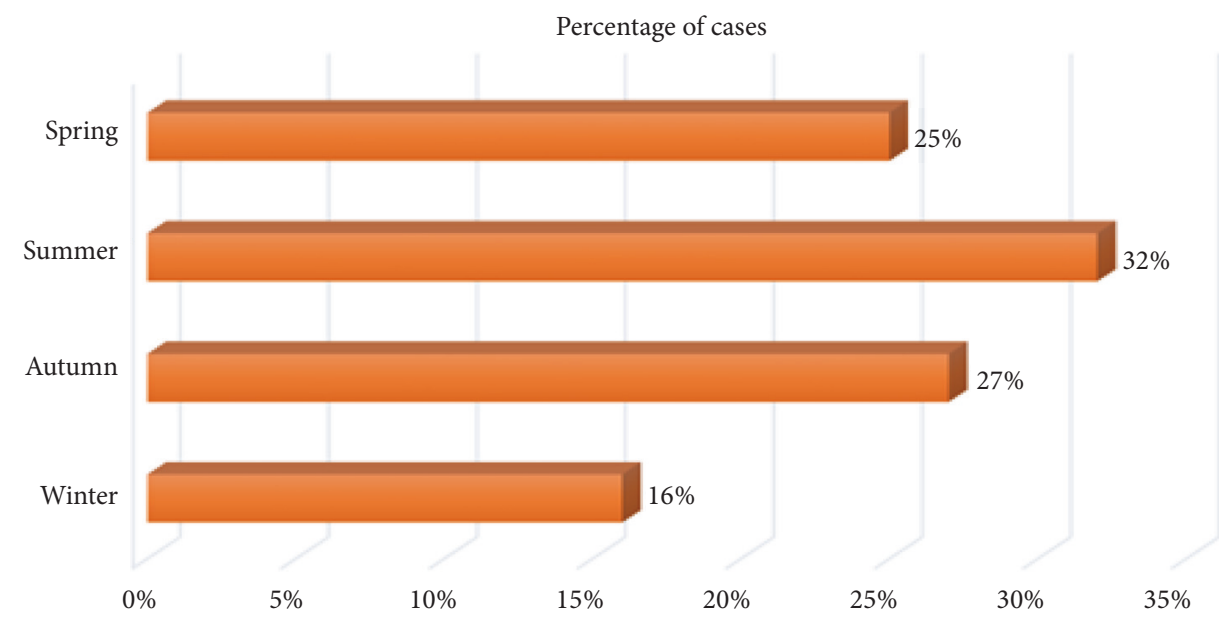

FIGURE 1: Distribution of cases according to seasons.

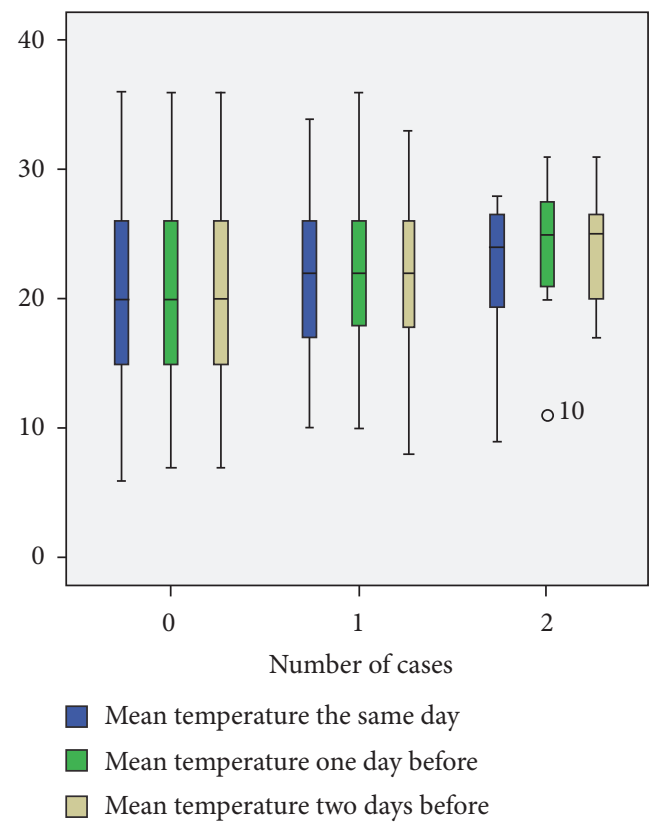

FIGURE 2: Association between the number of cases of pneumothorax and the mean temperature.

temperatures one day and two days before the occurrence of pneumothorax with increased risks of $3.8 \%$ and $3.6 \%$, respectively, for each $1^{\circ} \mathrm{C}$.

Considering the collinearity of these three variables (average temperature on the day of occurrence of pneumothorax, a day before and two days before), mean temperatures of all three days were calculated. Thus, an increase of mean temperature of the three days by $1^{\circ} \mathrm{C}$ augmented the risk of the onset of pneumothorax by $3.7 \%(p=0.003 ; \exp (B)=1.037$, 95\% CI [1.013-1.062]).

3.4.2. Mean Relative Humidity. Although mean relative humidity between days with and without pneumothorax did not differ significantly $(\mathrm{p}=0.33)$, a lower relative humidity

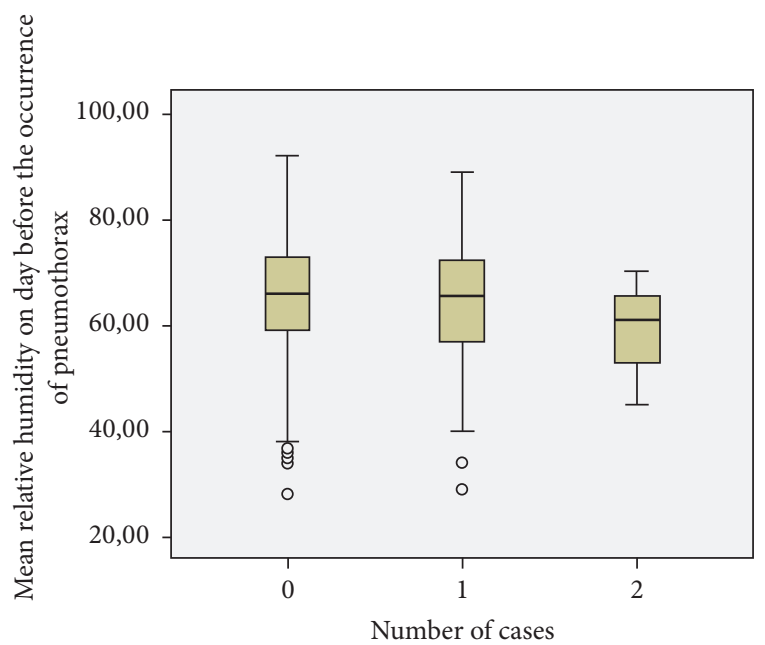

FIgURE 3: Association between mean humidity and the number of cases of pneumothorax.

one day before the occurrence of pneumothorax was related to the risk of its onset. The comparison of mean relative humidity averages one day before pneumothorax showed that this fall was similarly associated with the number of pneumothoraxes the next day with $\mathrm{p}=0.036$ as shown in Figure 3.

The mean relative humidity two days before the occurrence of pneumothorax did not appear to be associated with the risk of occurrence of pneumothorax $(\mathrm{p}=0.26)$.

Poisson regression showed that the decrease in mean relative humidity one day before of $1 \%$ was associated with an increased risk of developing a pneumothorax the next day by $1.6 \%(\mathrm{p}=0.02, \exp (\mathrm{B})=0.984,95 \% \mathrm{CI}[0.97-0.99])$.

3.4.3. Mean Atmospheric Pressure. Mean atmospheric pressure the same day, one day before, and two days before the occurrence of pneumothorax did not appear to be associated with an increased risk of pneumothorax. 


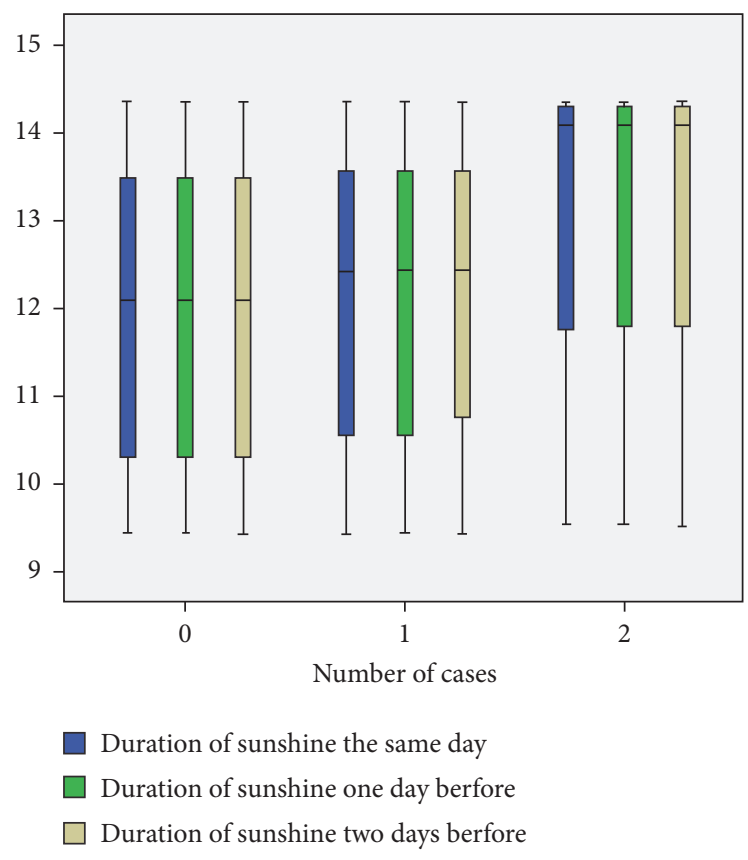

FIGURE 4: Distribution of mean duration of sunshine in the same day, one day before, and two days before the onset on pneumothorax according the number of cases of pneumothorax.

3.4.4. Mean Duration of Sunshine. The mean of duration of sunshine the same day, one day before, and two days before the occurrence of pneumothorax was statistically associated with the onset of this pathology with $p=0.008$ at the same day, $p=0.006$ one day before, and $p=0.005$ two days before. Indeed, this mean duration of sunshine was higher on the same day of pneumothorax, as well as one day, and two days before, compared to days without pneumothorax (Figure 4).

Moreover, the longer this duration was, the higher the number of cases was. Taking into account the collinearity of the mean duration of sunshine the same day, one day before, and two days before, Poisson regression analysis was performed considering the average of all three days. Thus, an increase of one hour in the average duration of sunshine during these 3 days was associated with an increased risk of pneumothorax of $14 \%(\mathrm{P}=0.002, \exp (\mathrm{B})=1.1495 \% \mathrm{CI}[1.04$ to 1.24$])$.

3.4.5. Rainfall and Thunderstorms. In our study, $17.6 \%$ of days of pneumothorax were rainy $(\mathrm{n}=321$ days). Rainfall occurring the same day, one day before, and two days before did not seem to be associated with a higher risk of pneumothorax ( $\mathrm{p}=0.98,0.83$, and 0.7 respectively).

During the study period, 142 days included the occurrence of thunderstorms which were not statistically associated with the occurrence of pneumothorax.

3.5. Main Results. A higher risk of occurrence of pneumothorax during summer was noted with an OR $=1.44$ (95\% CI [1.04-1.99]) and $p=0.0027$. This association was greater while comparing warm seasons (spring-summer-autumn) and cold season (winter), with a risk of occurrence of SP during the relatively warm seasons 1.81 times greater than in winter $(\mathrm{p}=$ $0.004, \mathrm{OR}=1.81(95 \% \mathrm{CI}[1.2-2.72])$ ).

We showed a significant increased risk of occurrence of a pneumothorax of $3.4 \%$ for each temperature rise of $1^{\circ} \mathrm{C}$. This association was observed for temperatures one day and two days before the occurrence of pneumothorax with increased risks of $3.8 \%$ and $3.6 \%$, respectively, for each $1^{\circ} \mathrm{C}$.

We noted that the decrease in mean relative humidity one day before of $1 \%$ was associated with an increased risk of developing a pneumothorax the next day by $1.6 \%(\mathrm{p}=0.02$, $\exp (B)=0.984,95 \%$ CI [0.97-0.99]). An increase of one hour in the average duration of sunshine during these 3 days was associated with an increased risk of pneumothorax of $14 \%(\mathrm{P}$ $=0.002, \exp (\mathrm{B})=1.1495 \% \mathrm{CI}[1.04$ to 1.24$])$.

\subsection{Other Analyses}

3.6.1. "Clusters " and Meteorological Parameters. In our study, the occurrence of clusters was associated with higher mean temperature in the same day, one day before and two days before with $\mathrm{p}=0.038, \mathrm{p} .=0.008$, and $\mathrm{p}=0.006$, respectively.

This same observation was made concerning the mean duration of sunshine two days before the occurrence of the cluster which was higher with $\mathrm{p}=0.05$.

In addition, the occurrence of thunderstorms two days before the occurrence of clusters was significantly associated with a risk multiplied by $1.96(\mathrm{p}=0.035, \mathrm{OR}=1.96,95 \% \mathrm{CI}$ [1.038-3.69]).

\subsubsection{Multivariate Analysis.}

Onset of SP and Variables of Interest. A multiple binary logistic regression was performed to determine the independent variables associated with the occurrence of a pneumothorax by transforming meteorological data into binary qualitative variables based on their quartiles. A selection of the most significant quartiles for a univariate analysis was previously performed. This preliminary analysis indicated that the occurrence of pneumothorax was significantly associated with an average temperature greater than or equal to $16^{\circ} \mathrm{C}(1 \mathrm{st}$ Quartile) with $\mathrm{p}=0.0022$ and $\mathrm{OR}=1.58$ (95\% CI [1.06 -2.33]). This association was also noted for temperatures greater than or equal to $20^{\circ} \mathrm{C}$ with $\mathrm{p}=0.003$ and $\mathrm{OR}=1.6$ (95\% CI [1.17$2.2]$ ). Thus, the increase in temperature from $\mathrm{Q} 1$ to $\mathrm{Q} 2$ (the median temperature) was associated with an increased risk of pneumothorax of $2 \%$.

After multiple binary logistic regression, only a mean temperature above the median of $20^{\circ} \mathrm{C}$ was associated with higher risk of pneumothorax occurrence by $60 \%$.

Onset of «Clusters » and Variables of Interest. Multiple binary logistic regression showed that the occurrence of "clusters" was significantly associated with the occurrence of thunderstorms two days before the occurrence of pneumothorax and the summer season. Thus, clusters would be 1.74 times more frequent in summer and their occurrence would be increased 
by $94 \%$ in case of occurrence of thunderstorms two days before their incidence.

\section{Discussion}

During the 5th century BC, Hippocrates thought that climate could play a role in worsening the health of people [13]. Many studies have suggested the possible intervention of weather conditions such as temperature, humidity, atmospheric pressure, or precipitations on the occurrence of several diseases. Among these associations, mention was made of gout, asthma, Behçet's disease, or the rupture of the abdominal aortic aneurysm $[14,15]$.

The effect of a sudden change of pressure on the occurrence of pneumothorax is still discussed. Several studies have been conducted to find a relationship.

Cran IR. and Rumbal CA. noted that the incidence of pneumothorax was higher among Royal Air Force personnel, which was an argument in favor of this theory [16]. In addition, Ohata M. and Suzuki H. showed in their studies that the atmospheric pressure had an effect on the air leakage within the pleural cavity through the emphysema bubble [17].

If the onset of SP was influenced by weather changes, it should be common in various locations throughout the world, with various climates. There have been some reports referring to correlations between the risk of pneumothorax and weather conditions but these were mostly from Europe and the United States [9, 11, 18-22].

4.1. Keys Results. Tunisia's climate has some specificities and to our knowledge, there are no Tunisian studies published on this subject. This study confirmed the well-established finding that men are much more susceptible to spontaneous pneumothorax than women probably due to higher smoking rates, greater height, and relatively smaller airways among men $[1,23-31]$.

In our study, young people without significant lung pathology were the most affected. The mean age was $28 \pm$ 17.11 years and the most represented age group was between 21 and 40 years old (58\%). Similar results have been found in the literature $[20,21,25-27,32]$.

4.2. Strengths and Limitations. This study has several strengths. First, it is the first study examining the effects of seasonal variations and changes in meteorological parameters on the occurrence of pneumothorax in a Mediterranean climate as in Tunisia. Sousse is the region that occupies the eastern center of Tunisia. It covers an area of $2669 \mathrm{~km}^{2}$ (1.6\% of the country's area). It is located on the Tunisian coastline. The region of Sousse has a Mediterranean coastal climate characterized by hot, dry summers, and mild, wet winters [31] .

Second, we carried out a study of a time series, including the collection of meteorological parameters over a period of 5 years with analysis of their possible relationship with the onset of SP, or the successive occurrence of several cases of pneumothorax in a short period. This method would be the method of choice to study the short-term relationship between meteorological parameters and acute health events, compared to other methods such as cross-case studies where we compare two periods of time and cases that will be their own control [33].

There are, however, some limitations to this study. In fact, during the study period, 200 cases of SP were collected after verification of the inclusion and exclusion criteria. The cases have been identified in the university hospitals where the management of SP is carried out in the region of Sousse. However, this number could be unrepresentative given the possibility of the management of this pathology in private clinics making the collection of cases not exhaustive.

4.3. Interpretation and Generalisability. Neither particular year nor seasons were found to be significantly associated with a higher risk of onset of SP. Celik B. et al. in Turkey have found that more cases occurred mainly in autumn with no statistical difference with other seasons. [25] Bulajich B. et al. in Belgrade showed a maximum number of cases of pneumothorax during winter, also with no significant difference with the other seasons [22] .

For Suarez-varela M., the percentage of cases during the spring was the largest (33.87\%) but without being significant [21] . Contrary to these findings, several studies have found no association between SP cases and seasons $[11,20,34]$.

Ozenne G. et al. have showed two frequency peaks: in summer and in winter with a significant association with humidity [35]. These authors explained that bronchoconstriction is induced by the humidity of the air in the airways and that this could play a role in the occurrence of pneumothorax [9].

The temperature of the air entering the human body is balanced with body temperature by crossing the mouth or nose and the airways to the alveolar space. The presence of an association between rising temperatures and the occurrence of pneumothorax is cited in several studies and cannot be ignored.

According to Celik B., Heyndrickx M., Smit HJ., Schieman $C$., and Haga T, there was no significant difference, comparing meteorological data between days without and with pneumothorax $[20,25,26,29,36]$.

However, other studies showed that an increase in mean temperature increased the risk of pneumothorax and supported our findings $[9,20,28,37]$.

Our results are comparable to those of a recent study conducted by Motono N. et al. in 2016, which noted an influence of mean temperature on the occurrence of spontaneous pneumothorax. Blebs and bubbles with a nonreturn valve would trap air. This air behaved according to the law of Boyle-Marriot (Pressure $*$ Volume $=$ Constant). Increased temperatures would participate in the expansion of the gases and therefore a risk of breaking the blebs. Although the air contained in these blebs is not influenced by the external temperature, the latter influences the atmospheric pressure which would lead to the same result [38].

Among the mechanisms responsible for the development of SP, we thought that, when the air inside the bleb bubble was trapped because of bronchospasm, this would cause an imbalance between the pressure gradient with 
the environment $[20,34]$. For others, the transpulmonary pressure gradient may be sufficient to cause pneumothorax following a fall in atmospheric pressure [9]. According to the literature, it has been argued that the change in atmospheric pressure could be the cause of a pneumothorax since this has been especially noticed by airline personnel [16].

Some authors believe that a sudden change in atmospheric pressure may lead to a SP. According to Bertolaccini L., there is no relationship between the occurrence of pneumothorax and atmospheric pressure changes. One might think that a longer exposure to these variations may be necessary to provoke the event. However, Scott GC. et al. only described the hospitalization of only one among four patients after a 4-day exposure to changes in atmospheric pressure $[19,39]$.

In our study, mean atmospheric pressure levels the same day, one day before, and two days before did not seem to be associated with a higher risk of pneumothorax.

In regard to the relative humidity, studies often suggest the lack of a relationship between relative humidity and the occurrence of SP. [25, 26, 28, 29, 40]

However, Ozenne G. et al. reported lower relative humidity during the days of pneumothorax [35]. These results were similar to those found in our study where the lower relative humidity, one day before the occurrence of SP, the greater the number of pneumothorax $(\mathrm{p}=0.036)$.

The explanation given by Ozenne G. et al. is that the decrease in relative humidity is accompanied by humidification of the airways with secondary bronchoconstriction, precipitating the onset of SP [35].

Regarding other meteorological parameters, Alifano et al. have noted the onset of clusters during or immediately following a fall in atmospheric pressure [11].

There is no consensus regarding the reasons for the apparent increase in the rate of SP or the factors precipitating its development. However, physicians have observed that patients with SP are admitted in clusters and changes in climate or related weather conditions are therefore suspected to be involved in the occurrence of SP.

Smit HJ. was the first to note that $73 \%$ of primitive pneumothoraxes were admitted as clusters. Based on his clinical findings, he defined the cluster as the hospitalization of two or more patients for SP with less than 3 days without episodes between the pneumothorax events $(95 \%, \mathrm{p}<0.001)$ [20] .

This was also the conclusion of Boulay F. et al. who noted the occurrence of $60 \%$ of SP cases as clusters, with an average of 2.7 patients in each cluster [20,36,41,42] .

In a study carried out in Turkey between 1996 and 2006, 669 episodes of SP were noticed and 472 appeared in 188 "clusters". The average clustered case was $2.5 \pm 0.8$ with a minimum of 2 episodes and a maximum of 7 [9].

For Vodicka J., 23.3\% of the cases were observed in 54 "clusters". This low rate was explained by the low number of cases recorded over a long period of time (22 years) [37].

Celik B. et al. found a relationship between these clusters and the increase in mean temperature $(\mathrm{p}=0.038)$, and this result was similar to ours [25]. However, we noticed the association between the occurrence of storms two days before the onset of SP and these clusters, which was not found by other authors.

\section{Conclusion}

In summary, we conclude that there is an association between the occurrence of SP and some metrological parameters.

Other studies have shown different results from ours and this could be explained by the differences that exist between regions in terms of climatic specificities and meteorological conditions.

Our study draws attention to this relationship that exists between seasonality and the onset of SP in the region of Sousse.

To our knowledge, it is the first study that was conducted in the southern side of the Mediterranean region to prove this correlation.

Our main result is the association between warm season, high mean temperature, and SP. This observation would explain the onset of clusters and allows a scientific approach to the "law of series" that clinicians note.

Expecting a higher number of cases during hot seasons, physicians can only be better prepared to manage them.

\section{Data Availability}

The meteorological data used to support the findings of this study are available from the corresponding author upon request.

\section{Conflicts of Interest}

The authors declare that they have no conflicts of interest.

\section{Authors' Contributions}

(1) Sana Aissa, Maher Maoua, Salsabil Selmi, Mohamed Kahloun, and Walid Naija are responsible for design and development of the study. (2) Sana Aissa, Maher Maoua, and Salsabil Selmi contributed to data analysis and interpretation. (3) Sana Aissa, Maher Maoua, Wafa Benzarti, and Imen Gargouri contributed to writing the article or critical analysis leading to significant changes to the intellectual content. (4) Sana Aissa, Maher Maoua, Salsabil Selmi, Wafa Benzarti, Imen Gargouri, Ahmed Abdelghani, Abdelhamid Garrouche, Abdelaziz Hayouni, Mohamed Kahloun, Walid Naija, Nejib Mrizek, and Mohamed Benzarti contributed to final approval of the version submitted after critical review.

\section{Acknowledgments}

We acknowledge the help of the National Institute of Meteorology that provided us with the meteorological data in the study period. This original research is based on the doctoral thesis of Dr Salsabil Selmi supported on December 2017 in the Faculty of Medicine Ibn Jazzar in Sousse (Tunisia). The doctoral thesis was directed by the 2 Associate Professors: Dr Sana Aissa and Dr Maher Maoua. The abstract of the present 
research was presented before in European Respiratory Society (ERS) International Congress, Milan 2017.

\section{Supplementary Materials}

The meteorological data and patients data are saved in an SPSS document (attached), the document for data collection in word version. (Supplementary Materials)

\section{References}

[1] M. Noppen, "Spontaneous pneumothorax: epidemiology, pathophysiology and cause," European Respiratory Review, vol. 19, no. 117, pp. 217-219, 2010.

[2] S. A. Sahn and J. E. Heffner, "Spontaneous pneumothorax," The New England Journal of Medicine, vol. 342, no. 12, pp. 868-874, 2000.

[3] L. Bense, G. Eklund, and L. G. Wiman, "Bilateral bronchial anomaly: a pathogenetic factor in spontaneous pneumothorax," American Review of Respiratory Disease, vol. 146, no. 2, pp. 513516, 1992.

[4] T.-W. Huang, Y.-L. Cheng, C. Tzao et al., "Factors related to primary bilateral spontaneous pneumothorax," The Thoracic and Cardiovascular Surgeon, vol. 55, no. 5, pp. 310-312, 2007.

[5] R. W. Light, "Management of spontaneous pneumothorax," American Review of Respiratory Disease, vol. 148, no. 1, pp. 245248, 1993.

[6] D. Gupta, A. Hansell, T. Nichols, T. Duong, J. G. Ayres, and D. Strachan, "Epidemiology of pneumothorax in England," Thorax, vol. 55, no. 8, pp. 666-671, 2000.

[7] M. Henry, T. Arnold, J. Harvey et al., "BTS guidelines for the management of spontaneous pneumothorax," Thorax, vol. 58, supplement 2, pp. 1-59, 2003.

[8] L. Bense, L. G. Wiman, and G. Hedenstierna, "Onset of symptoms in spontaneous pneumothorax: correlations to physical activity," European Journal of Respiratory Diseases, vol. 71, pp. 181-186, 1987.

[9] B. Özpolat, A. Gözübüyük, B. Koçer, R. Yazkan, K. Dural, and O. Genç, "Meteorological conditions related to the onset of spontaneous pneumothorax," The Tohoku Journal of Experimental Medicine, vol. 217, no. 4, pp. 329-334, 2009.

[10] M. Noppen, S. Verbanck, J. Harvey et al., "Music: a new cause of primary spontaneous pneumothorax," Thorax, vol. 59, no. 8 , pp. 722-724, 2004.

[11] M. Alifano, S. N. F. Parri, B. Bonfanti et al., "Atmospheric pressure influences the risk of pneumothorax: beware of the storm!," CHEST, vol. 131, no. 6, pp. 1877-1882, 2007.

[12] Koninklijk Nederlands Meteorologish Instituut (KNMI), Handbook for the meteorological Observation, 2000, http://projects .knmi.nl/hawa/pdf/Handbook_H01_H06.pdf.

[13] V. Danielides, C.-S. Nousia, A. Bartzokas, C. J. Lolis, M. Kateri, and A. Skevas, "Weather conditions and sudden sensorineural hearing loss," BMC Ear, Nose, and Throat Disorders, vol. 2, pp. $1-8,2002$.

[14] A. Celenza, J. Fothergill, E. Kupek, and R. J. Shaw, “Thunderstorm associated asthma: a detailed analysis of environmental factors," British Medical Journal, vol. 312, no. 7031, pp. 604-607, 1996.

[15] S. Danet, F. Richard, M. Montaye et al., "Unhealthy effects of atmospheric temperature and pressure on the occurrence of myocardial infarction and coronary deaths," Circulation, vol. 100, pp. e1-e7, 1999.

[16] I. R. Cran and C. A. Rumball, "Survey of spontaneous pneumothoraces in the Royal Air Force," Thorax, vol. 22, no. 5, pp. 462-465, 1967.

[17] M. Ohata and H. Suzuki, "Pathogenesis of spontaneous pneumothorax. With special reference to the ultrastructure of emphysematous bullae," CHEST, vol. 77, no. 6, pp. 771-776, 1980.

[18] L. Bense, "Spontaneous pneumothorax related to falls in atmospheric pressure," European Journal of Respiratory Diseases, vol. 65, pp. 544-546, 1984.

[19] G. C. Scott, R. Berger, and H. E. McKean, "The role of atmospheric pressure variation in the development of spontaneous pneumothoraces," American Review of Respiratory Disease, vol. 139, no. 3, pp. 659-662, 1989.

[20] H. J. M. Smit, W. L. Devillé, F. M. N. H. Schramel, A. J. M. Schreurs, T. G. Sutedja, and P. E. Postmus, "Atmospheric pressure changes and outdoor temperature changes in relation to spontaneous pneumothorax," CHEST, vol. 116, no. 3, pp. 676681, 1999.

[21] M. Morales Suarez-Varela, M. I. Martinez-Selva, A. LlopisGonzalez, J. L. Martinez-Jimeno, and P. Plaza-Valia, "Spontaneous pneumothorax related with climatic characteristics in the Valencia area (Spain)," European Journal of Epidemiology, vol. 16, no. 2, pp. 193-198, 2000.

[22] B. Bulajich, D. Subotich, D. Mandarich, R. V. Kljajich, and M. Gajich, "Influence of atmospheric pressure, outdoor temperature, and weather phases on the onset of spontaneous pneumothorax," Annals of Epidemiology, vol. 15, no. 3, pp. 185190, 2005.

[23] L. Bense, G. Eklund, and L.-G. Wiman, "Smoking and the increased risk of contracting spontaneous pneumothorax," CHEST, vol. 92, no. 6, pp. 1009-1012, 1987.

[24] A. Bobbio, A. Dechartres, S. Bouam et al., "Epidemiology of spontaneous pneumothorax: gender-related differences," Thorax, vol. 70, no. 7, pp. 653-658, 2015.

[25] B. Çelik, H. Kefeli Çelik, H. Hamzaçebi, H. Demir, K. Furtun, and C. Ortamevzi, "The role of meteorological conditions on the development of spontaneous pneumothorax," The Thoracic and Cardiovascular Surgeon, vol. 57, no. 07, pp. 409-412, 2009.

[26] T. Haga, M. Kurihara, H. Kataoka, and H. Ebana, "Influence of weather conditions on the onset of primary spontaneous pneumothorax: positive association with decreased atmospheric pressure," Annals of Thoracic and Cardiovascular Surgery, vol. 19, no. 3, pp. 212-215, 2013.

[27] R. Díaz, M. M. Díez, M. J. Medrano et al., "Influence of atmospheric pressure on the incidence of spontaneous pneumothorax," Cirugía Española (English Edition), vol. 92, no. 6, pp. 415-420, 2014.

[28] G. Zhang, R. Gao, J. Fu, X. Jin, Y. Zhang, and Z. Wang, "Climatic conditions and the onset of primary spontaneous pneumothorax: an investigation of the influence of solar terms," Medical Principles and Practice, vol. 21, no. 4, pp. 345-349, 2012.

[29] M. Heyndrickx, J. Le Rochais, P. Icard, O. Cantat, and G. Zalcman, "Do atmospheric conditions influence the first episode of primary spontaneous pneumothorax?" Interactive CardioVascular and Thoracic Surgery, vol. 21, no. 3, pp. 296-300, 2015.

[30] D. Contou and B. Maitre, Pneumothorax spontanés, EMC, 2014, https://www.em-consulte.com/article/874519/pneumothoraxspontanes. 
[31] M. Mohamed, Le climat agricole au sahel Tunisien et les changements climatiques, Université du Québéc à Montréal, 2009, Mémoire de maitrise en géographie, https://archipel.uqam.ca/ 2466/1/M10930.pdf.

[32] G. Zhang, J. Yang, H. Fu, J. Zheng, Y. Li, and X. Li, "Structural and electronic properties of the hydrogen storage compound $\mathrm{Ca}(\mathrm{BH} 4) 2 \cdot 2 \mathrm{NH} 3$ from first-principles," Computational Materials Science, vol. 54, no. 1, pp. 345-349, 2012.

[33] L. Filleul, A. Zeghnoun, C. Declercq et al., "Relations à court terme entre la pollution atmosphérique urbaine et la mortalité respiratoire?: la place des études temporelles," Revue des Maladies Respiratoires, vol. 18, pp. 387-395, 2001.

[34] C.-H. Chen, Y. R. Kou, C.-S. Chen, and H.-C. Lin, "Seasonal variation in the incidence of spontaneous pneumothorax and its association with climate: a nationwide population-based study," Respirology, vol. 15, no. 2, pp. 296-302, 2010.

[35] G. Ozenne, P. Poignie, J.-P. Lemercier et al., "Meteorological conditions and spontaneous pneumothorax. A retrospective study of 165 cases in the Rouen area," Revue de Pneumologie Clinique, vol. 40, no. 1, pp. 27-33, 1984.

[36] C. Schieman, A. Graham, G. Gelfand et al., "Weather and chinook winds in relation to spontaneous pneumothoraces," Canadian Journal of Surgery, vol. 52, pp. E151-E155, 2009.

[37] J. Vodička, Š. Vejvodová, D. Šmíd et al., "Do weather phenomena have any influence on the occurrence of spontaneous pneumothorax?" Archivos de Bronconeumología (English Edition), vol. 52, no. 5, pp. 239-243, 2016.

[38] N. Motono, S. Maeda, R. Honda et al., "Atmospheric temperature and pressure influence the onset of spontaneous pneumothorax," The Clinical Respiratory Journal, vol. 12, no. 2, pp. 557-562, 2018.

[39] L. Bertolaccini, L. Alemanno, G. Rocco, and C. Cassardo, "Air pollution, weather variations and primary spontaneous pneumothorax," Journal of Thoracic Disease, vol. 2, no. 1, pp. 9$15,2010$.

[40] L. Bertolaccini, A. Viti, L. Boschetto et al., "Analysis of spontaneous pneumothorax in the city of Cuneo: environmental correlations with meteorological and air pollutant variables," Surgery Today, vol. 45, no. 5, pp. 625-629, 2015.

[41] F. Boulay, O. Sisteron, T. Chevallier, and B. Blaive, "Predictable mini-epidemics of spontaneous pneumothorax: haemoptysis too?” The Lancet, vol. 351, no. 9101, p. 522, 1998.

[42] H. J. M. Smit, W. L. Devillé, F. M. N. H. Schramel, and P. E. Postmus, "Spontaneous pneumothorax: predictable miniepidemics?” The Lancet, vol. 350, no. 9089, p. 1450, 1997. 


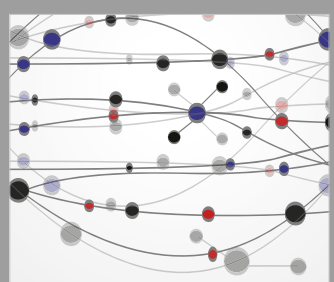

The Scientific World Journal
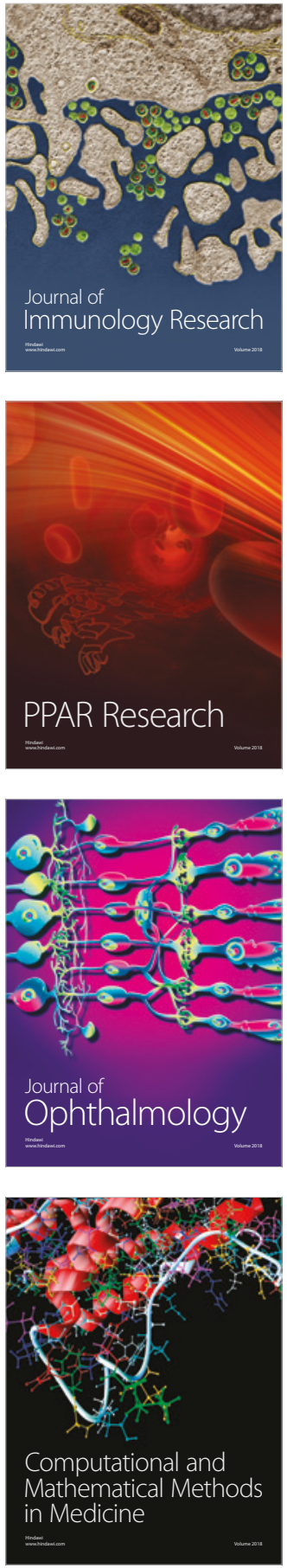

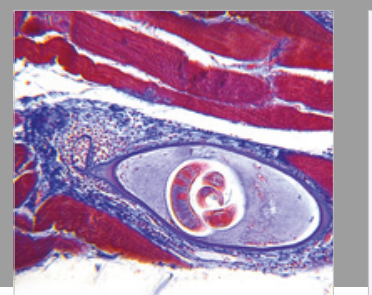

Gastroenterology Research and Practice

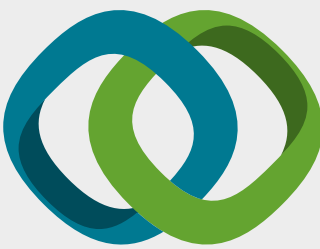

\section{Hindawi}

Submit your manuscripts at

www.hindawi.com
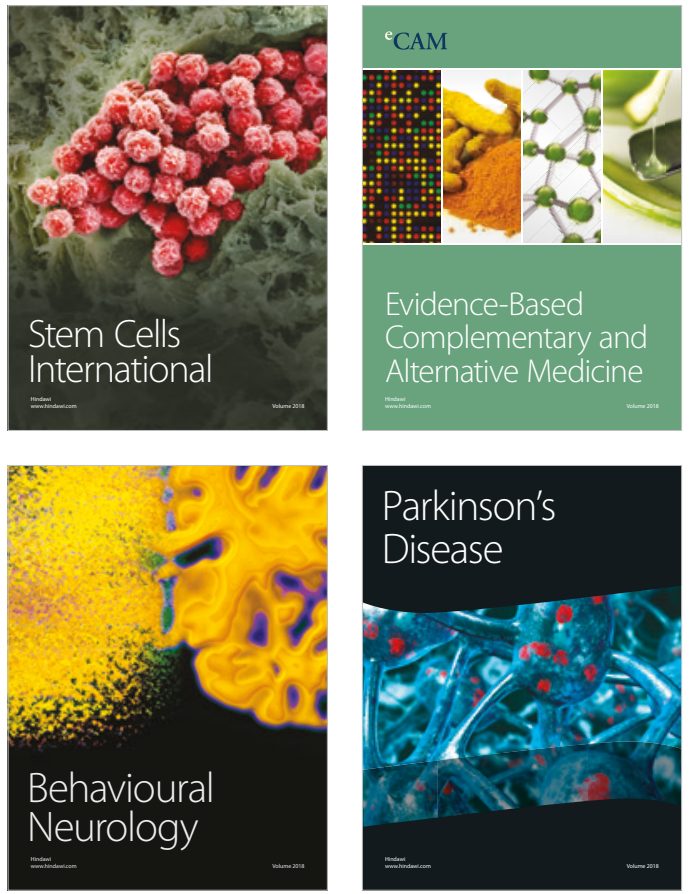

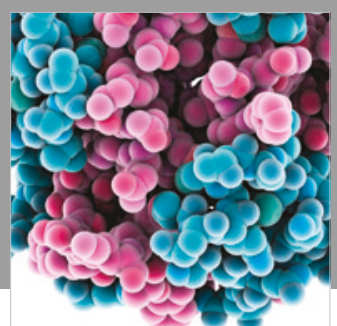

ournal of

Diabetes Research

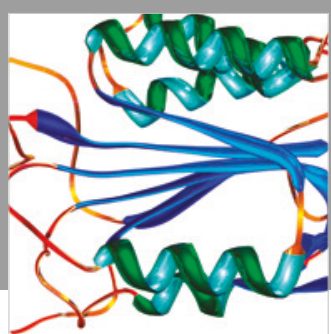

Disease Markers
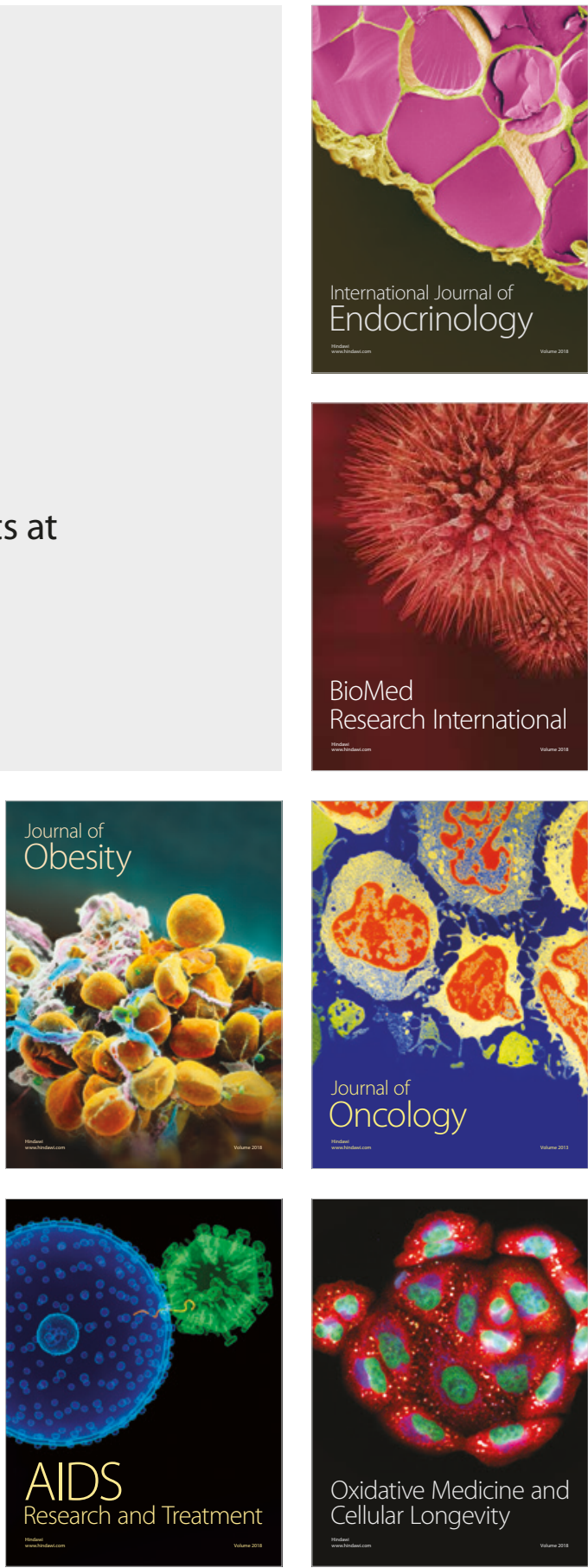